\title{
BMJ Open Repeat screening for syphilis in pregnancy as an alternative screening strategy in the UK: a cost- effectiveness analysis
}

\author{
Susie Huntington (D) , ${ }^{1}$ Georgie Weston (D) , ${ }^{1}$ Farah Seedat (D) , ${ }^{2}$ John Marshall (D) , \\ Heather Bailey (D) , ${ }^{3}$ Marc Tebruegge, ${ }^{4,5}$ Imtyaz Ahmed, ${ }^{1}$ Katy Turner (D) , ${ }^{6}$ \\ Elisabeth Adams (D) ${ }^{1}$
}

To cite: Huntington $S$, Weston G, Seedat F, et al. Repeat screening for syphilis in pregnancy as an alternative screening strategy in the UK: a cost-effectiveness analysis. BMJ Open 2020;10:e038505. doi:10.1136/ bmjopen-2020-038505

- Prepublication history and additional material for this paper are available online. To view these files, please visit the journal online (http://dx.doi. org/10.1136/bmjopen-2020038505).

Received 16 March 2020 Revised 19 August 2020 Accepted 04 October 2020

D) Check for updates

(C) Author(s) (or their employer(s)) 2020. Re-use permitted under CC BY-NC. No commercial re-use. See rights and permissions. Published by BMJ.

For numbered affiliations see end of article.

Correspondence to Dr Susie Huntington; susie.huntington@aquariusph. com

\section{ABSTRACT}

Objectives To assess the cost-effectiveness of universal repeat screening for syphilis in late pregnancy, compared with the current strategy of single screening in early pregnancy with repeat screening offered only to high-risk women.

Design A decision tree model was developed to assess the incremental costs and health benefits of the two screening strategies. The base case analysis considered short-term costs during the pregnancy and the initial weeks after delivery. Deterministic and probabilistic sensitivity analyses and scenario analyses were conducted to assess the robustness of the results.

Setting UK antenatal screening programme.

Population Hypothetical cohort of pregnant women who access antenatal care and receive a syphilis screen in 1 year. Primary and secondary outcome measures The primary outcome was the cost to avoid one case of congenital syphilis (CS). Secondary outcomes were the cost to avoid one case of intrauterine fetal demise (IUFD) or neonatal death and the number of women needing to be screened/treated to avoid one case of CS, IUFD or neonatal death. The cost per quality-adjusted life year gained was assessed in scenario analyses.

Results Base case results indicated that for pregnant women in the UK ( $n=725$ 891), the repeat screening strategy would result in 5.5 fewer cases of CS (from 8.8 to 3.3), 0.1 fewer cases of neonatal death and 0.3 fewer cases of IUFD annually compared with the single screening strategy. This equates to an additional £1.8 million per case of CS prevented. When lifetime horizon was considered, the incremental cost-effectiveness ratio for the repeat screening strategy was £120 494 .

Conclusions Universal repeat screening for syphilis in pregnancy is unlikely to be cost-effective in the current UK setting where syphilis prevalence is low. Repeat screening may be cost-effective in countries with a higher syphilis incidence in pregnancy, particularly if the cost per screen is low.

\section{INTRODUCTION}

Syphilis is a bacterial sexually transmitted infection (STI) caused by Treponema pallidum subspecies pallidum. The prevalence of syphilis in the UK is low, however, the number

\section{Strengths and limitations of this study}

- This is the first health economic analysis to assess the cost-effectiveness of a repeat screening strategy for syphilis in pregnancy compared with a single screen strategy within the UK setting.

- Experts provided input to inform the model parameters and validate the model structure and assumptions.

- Extensive sensitivity analyses were performed to assess uncertainty in the results.

- A lack of long-term data on the costs and utilities associated with congenital syphilis meant the focus of the analysis was on the short-term costs and health benefits, with the incremental cost-effectiveness ratio being calculated in scenario analyses.

of new diagnoses has increased over the last decade. In women, the number of cases rose from 345 in 2009 to 550 in $2018 .{ }^{1}$

Congenital syphilis (CS) occurs via vertical transmission of syphilis during the pregnancy which can occur during any trimester and at any of the four stages of syphilis infection. The highest risk of transmission, however, occurs in primary syphilis when sores or chancres are present. Adverse pregnancy outcomes can include intrauterine fetal demise (IUFD), prematurity and neonatal death, with the risk being considerably higher in women with untreated syphilis than in pregnant women with no syphilis or in pregnant women who receive adequate treatment for syphilis following diagnosis at first trimester screening. ${ }^{2}$ The risk of CS is difficult to quantify due to the small number of cases, the wide range of disease presentations and probable underdiagnosis. There is evidence, although limited, that the risk of CS is higher if women become infected while pregnant than if they have active syphilis at 
the time of conception. ${ }^{23}$ In infants born with CS, the infection can cause reduced growth and development, neurological impairment, bone deformities and hearing loss. ${ }^{45}$ Infants treated with intravenous benzylpenicillin sodium in the first 2 months of life are reported to have a good short-term prognosis, but long-term outcomes have not been investigated in detail. ${ }^{67}$

In the UK, routine antenatal screening for syphilis, hepatitis B and HIV is offered to all pregnant women at their first routine antenatal appointment, usually before 12 weeks gestation, or later, for the small proportion of women who first present in their second or third trimester. ${ }^{8}$ Women who decline screening are formally reoffered and screening coverage currently exceeds $99.6 \% .^{9-11}$ Blood samples are initially tested using an enzyme immunoassay (EIA) with a T. pallidum particle agglutination assay (TPPA) performed on the same specimen to confirm a positive result. Women with a positive TPPA result are referred to a sexual health clinic to assess whether they have an active infection which requires treatment or a previous infection not requiring treatment. It is possible that women who screen negative for syphilis become positive later in pregnancy, either because they become infected with syphilis, or because their infection was too recent for a detectable antibody response to have been mounted at the time of the first screen. Management guidelines, outside the national screening programme, recommend that women are offered repeat testing for syphilis in late pregnancy if they have been diagnosed and treated for syphilis in the first trimester, if they consider themselves to be at risk of infection, or have a single 'high-risk' exposure. ${ }^{11}{ }^{12}$ Assessing women's risk can be problematic and risk can change during pregnancy. Data on coverage of repeat testing or management is not routinely collected. In 2011-2013, the Surveillance of Antenatal Syphilis Screening (SASS) study was conducted to provide quantitative data on the performance of the screening pathway. ${ }^{13}$

Syphilis prevalence in pregnant women is low, the SASS study found that $0.04 \%(1 / 2800)$ of pregnant women required treatment for syphilis in 2010-2011, although the prevalence may have subsequently increased. ${ }^{13}$ CS incidence is also low and below the WHO elimination threshold of $\leq 0.5 / 1000 .{ }^{14}$ However, between March 2016 and January 2017, four cases of CS occurred in the UK in women who screened negative for syphilis in pregnancy. ${ }^{15}$ None of whom had a repeat screen during pregnancy, and confirmatory testing later showed that they had acquired syphilis while pregnant. These infections would likely have been diagnosed and treated if repeat screening in late pregnancy was offered to all pregnant women, an approach that has not been assessed in the UK. Two models assessed the cost-effectiveness of universal repeat screening in the USA, where the prevalence of syphilis in pregnant women is higher than in the UK. One found that universal repeat screening was cost saving, ${ }^{16}$ while the other found that it cost US\$419 842 per CS case avoided. ${ }^{17}$
To inform the UK National Screening Committee (UK NSC) and in response to an increase in syphilis diagnoses in the UK and the continued occurrence of CS cases each year, although very small numbers, the clinical and costeffectiveness of universal screening in the first and third trimesters, as an alternative strategy to universal screening in the first trimester only, was assessed.

\section{METHODS \\ Model structure}

A decision tree model in TreeAge (TreeAge Pro 2019, R2. TreeAge Software, Williamstown, Massachusetts, USA) was developed to assess the incremental costs and health benefits of universal repeat screening for antenatal syphilis compared with universal screening in the first trimester only (figure 1). For both screening strategies, the decision tree followed the true disease state of women and the population was split into women screened in the first/second trimester and women screened in the third trimester (ie, late presenters who would miss the opportunity for repeat screening). Women with a positive result received treatment at a sexual health clinic plus any additional testing required. Each branch (with or without syphilis) ended with the same pregnancy outcomes: IUFD or no IUFD, the latter resulting in a preterm or term delivery and either neonatal death, an infant with CS, or an infant with no CS (online supplemental figure $\mathrm{S} 1$ ).

The model included pregnant women in the UK who accessed antenatal care and received a syphilis screen in 2018 (the latest available data at the time). Pregnant women who were not screened $(0.04 \%)$ were not included, since any change to the screening strategy would have no impact on their outcomes. Costs were considered from the UK healthcare system perspective. Social care costs were not included in the short term. To assess the overall impact of the two screening strategies, the costs for all pregnancy outcomes for all women screened were considered, not just costs for women with syphilis. The model threshold for early versus late first screen was 28 weeks gestation, that is, the start of the third trimester. The time horizon for the base case analysis considered short-term costs during the pregnancy and the perinatal period. Lifetime costs and utilities were not used in the base case analysis (but were considered in scenario analysis) as the data available on the long-term costs and utilities associated with CS were limited and include too much uncertainty to provide a robust result. See online supplemental table S1 for base case model assumptions.

\section{Model parameters}

Data were sought using PubMed, Google Scholar, online searches, references within papers, from experts and laboratory contacts and by data request to Public Health Agencies. 


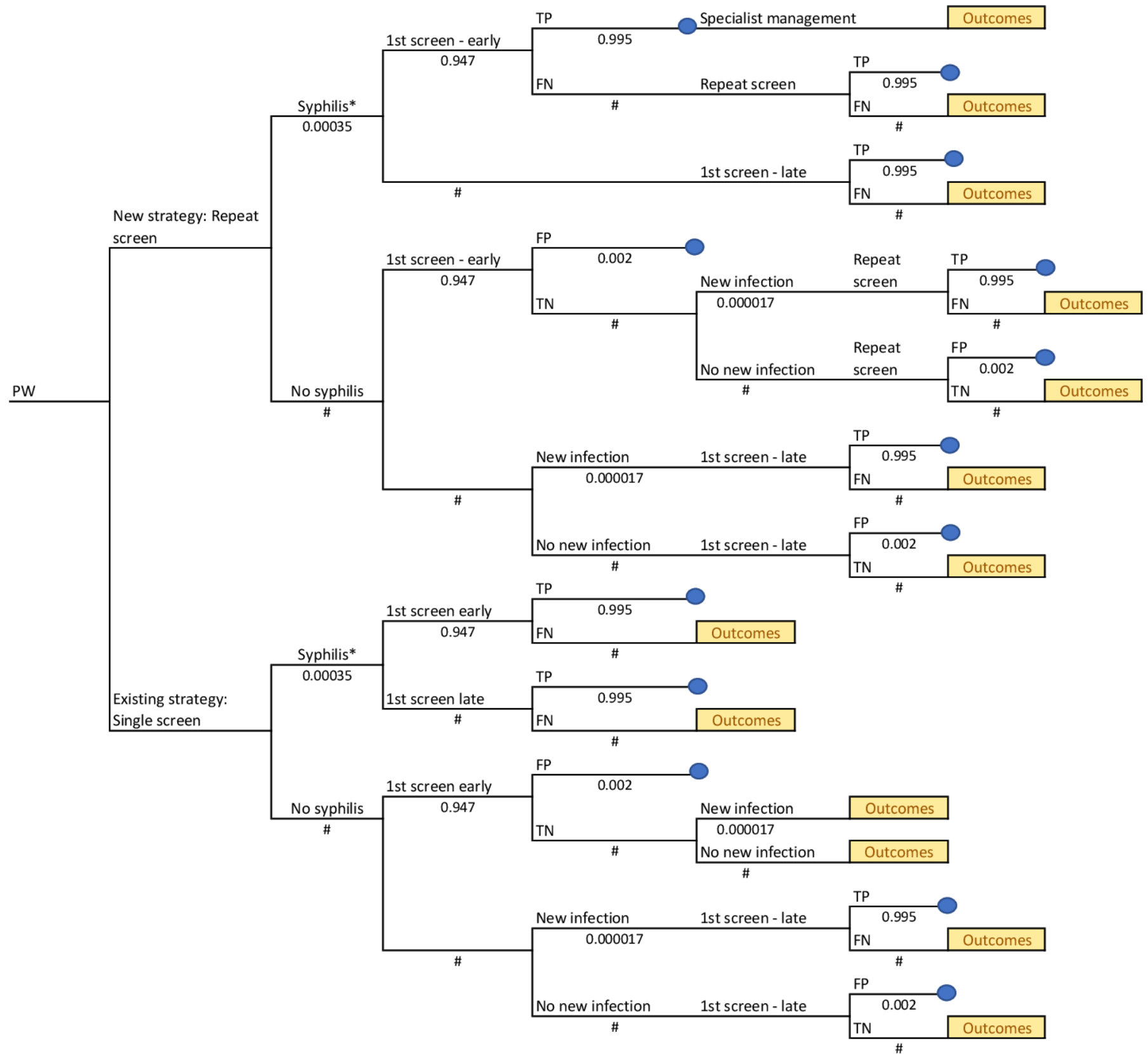

Figure 1 Overview of decision tree comparing single screening with universal repeat screening of syphilis in pregnancy. With reference to the timing of $1^{\text {st }}$ syphilis screen, 'early' refers to $1^{\text {st }}$ or $2^{\text {nd }}$ trimester and 'late' refers to the third trimester. Where branches split, the probabilities are shown in the top branch, with \# indicating (1-probability). Blue circle indicates referral to specialist management for treatment and the same seven pregnancy outcomes (as is shown in the top branch). Each branch ends with the same outcomes, but with different probabilities for each branch. Pregnancy outcomes are presented in online supplemental figure S1. FN, false negative result; FP, false positive result; PW, pregnant women; TN, true negative result; TP, true positive result.

\section{Clinical parameters}

Key clinical parameters were derived from published data and national surveillance data. Where data were only available from outside the UK, they were scaled to reflect UK pregnancy outcomes and syphilis prevalence. See table 1 for clinical parameters and methods of estimation. Furthermore, data from a large meta-analysis ${ }^{18}$ were adjusted to the UK setting to estimate the probability of each pregnancy outcome (online supplemental tables S2-S5).

\section{Cost parameters}

Cost parameters are presented in table 1. National Health Service (NHS) tariff costs or published costs from the UK were used where possible. Where no UK data were available, microcosting was used to calculate costs-informed by clinical guidelines, expert opinion and incorporating published NHS costs and tariffs where possible. To estimate the additional lifetime cost of CS, cost estimates from outside the UK were converted to pound sterling $(£) .{ }^{19}$ Where necessary, costs were 
Table 1 Clinical and cost parameters for model comparing single screening with universal repeat screening of syphilis in pregnancy in the UK

\begin{tabular}{|c|c|c|c|c|c|}
\hline & $\begin{array}{l}\text { Baseline } \\
\text { value }\end{array}$ & Low & High & Distribution & Note \\
\hline \multicolumn{6}{|l|}{ Clinical parameters } \\
\hline $\begin{array}{l}\text { Total number of women } \\
\text { in model (representing } \\
1 \text { year) }\end{array}$ & 725891 & - & - & - & $\begin{array}{l}\text { Based on number of deliveries in the UK } \\
\text { in } 2017 / 2018 \text { and the screening uptake. } \\
\text { See online supplemental table S6. }\end{array}$ \\
\hline $\begin{array}{l}\text { Probability of having } \\
\text { syphilis at the start of } \\
\text { pregnancy }\end{array}$ & 0.00035 & 0.00028 & 0.00042 & Beta & $\begin{array}{l}\text { Data derived from } 2011 \text { SASS data }{ }^{13} \\
\text { (England only }(244 / 691,494)) \text {. } \\
\text { Assume same risk in other UK countries. }\end{array}$ \\
\hline $\begin{array}{l}\text { Probability of becoming } \\
\text { infected with syphilis } \\
\text { during pregnancy }\end{array}$ & 0.000017 & 0.0000017 & 0.00012 & Beta & $\begin{array}{l}\text { Incidence was estimated using } \\
\text { published incidence and prevalence } \\
\text { data from USA scaled to reflect UK } \\
\text { prevalence. }{ }^{132}\end{array}$ \\
\hline $\begin{array}{l}\text { Probability of receiving } \\
\text { syphilis screen before } \\
28 \text { weeks gestation }\end{array}$ & 0.947 & 0.936 & 0.984 & Beta & $\begin{array}{l}\text { Estimate based on gestational week at } \\
\text { first antenatal attendance. See online } \\
\text { supplemental table S7. The low value is } \\
\text { in line with results from SASS study. }{ }^{13} \\
\text { The high value is in line with data from } \\
\text { Northern Ireland which (from the UK } \\
\text { countries) has the highest proportion of } \\
\text { women attending before } 28 \text { weeks. }\end{array}$ \\
\hline $\begin{array}{l}\text { Probability of true } \\
\text { positive result }\end{array}$ & 0.995 & 0.984 & 1.00 & Beta & $\begin{array}{l}\text { Based on the average test sensitivity of } \\
\text { five ElA assays used in the UK. High and } \\
\text { low values are based on best and worst } \\
\text { test performance of assays used in the } \\
\text { UK. }{ }^{2829}\end{array}$ \\
\hline $\begin{array}{l}\text { Probability of false } \\
\text { negative resultt }\end{array}$ & 0.005 & 0.016 & 0.00 & Beta & $\begin{array}{l}\text { Based on the average test sensitivity of } \\
\text { five ElA assays used in the UK. High and } \\
\text { low values are based on best and worst } \\
\text { test performance of assays used in the } \\
\text { UK. }\end{array}$ \\
\hline $\begin{array}{l}\text { Probability of true } \\
\text { negative result }\end{array}$ & 0.998 & 0.999 & 0.99 & Beta & $\begin{array}{l}\text { Based on average test specificity of five } \\
\text { ElA assays }(99.8 \%) \text { used in the UK. } \\
\text { High and low are estimates. }{ }^{28} 29\end{array}$ \\
\hline $\begin{array}{l}\text { Probability of false } \\
\text { positive resultł }\end{array}$ & 0.002 & 0.001 & 0.01 & Beta & $\begin{array}{l}\text { Based on average test specificity of five } \\
\text { EIA assays (99.8\%) used in the UK. High } \\
\text { and low are estimates. }{ }^{28} 29\end{array}$ \\
\hline
\end{tabular}

\section{Cost parameters (£)}

Syphilis screen

Estimated using microcosting. Screening is performed at the same time as other antenatal blood teststhis would also be the case for repeat screening at 28 weeks gestation. See online supplemental table S8.

\section{Management of women $314.09 \quad 251.27 \quad 376.91 \quad$ Gamma} diagnosed with syphilis in pregnancy Clinical management by sexual health clinician estimate based on London Integrated Sexual Health Tariff. ${ }^{33}$ See online supplemental table S9.

\begin{tabular}{|c|c|c|c|c|c|}
\hline $\begin{array}{l}\text { Intrauterine fetal } \\
\text { demise (IUFD)* }\end{array}$ & 4356.80 & 3485.44 & 5228.16 & Gamma & $\begin{array}{l}\text { Estimate based on } 2013 / 2014 \text { published } \\
\text { estimate from UK inflated to } 2017 / 2018 \\
\text { costs. }^{34}\end{array}$ \\
\hline
\end{tabular}


Table 1 Continued

\begin{tabular}{|c|c|c|c|c|c|}
\hline & $\begin{array}{l}\text { Baseline } \\
\text { value }\end{array}$ & Low & High & Distribution & Note \\
\hline Preterm delivery & 7100.37 & 5680.30 & 8520.45 & Gamma & $\begin{array}{l}\text { Estimate based on UK costs for deliver } \\
\text { at } 32-33 \text { weeks and } 34-36 \text { weeks } \\
\text { gestation (inflated from } 2010 / 2011 \\
\text { costs). }{ }^{35} \text { UK data on gestational age } \\
\text { at delivery (online supplemental table } \\
\text { S10) were then used to calculate the } \\
\text { proportion of deliveries at } 32-33(28 \%) \\
\text { and } 34-36 \text { weeks }(72 \%)\end{array}$ \\
\hline
\end{tabular}

\begin{tabular}{lllll}
$\begin{array}{l}\text { Term delivery }(37+ \\
\text { weeks) }\end{array}$ & 2034.62 & 1627.69 & 2441.54 & Gamma \\
\hline Neonatal death $\dagger$ & 5805.80 & 4644.64 & 6966.96 & Gamma
\end{tabular}

Estimate based on published cost using inflated 2010/2011 UK data. ${ }^{35}$

Estimated using cost of IUFD plus additional hospital costs. See online supplemental table S11.

\begin{tabular}{|c|c|c|c|c|c|}
\hline $\begin{array}{l}\text { CS testing and } \\
\text { treatment }\end{array}$ & 6607.68 & 5286.14 & 7929.21 & Gamma & $\begin{array}{l}\text { Estimated using microcosting. See } \\
\text { online supplemental tables S12 and } \\
\text { S13. }\end{array}$ \\
\hline CS neonatal screen & 245.25 & 196.20 & 294.30 & Gamma & $\begin{array}{l}\text { Screening test for neonates born to } \\
\text { women treated for syphilis in pregnancy. } \\
\text { Estimated using microcosting. See } \\
\text { online supplemental table S14. }\end{array}$ \\
\hline
\end{tabular}

\begin{tabular}{|c|c|c|c|c|c|}
\hline $\begin{array}{l}\text { CS lifetime healthcare } \\
\text { cost }\end{array}$ & 80423.37 & - & - & Gamma & $\begin{array}{l}\text { Average additional lifetime healthcare } \\
\text { costs attributable to CS based on cost } \\
\text { estimate for cerebral palsy (estimate } \\
\text { from 2000). }{ }^{22}\end{array}$ \\
\hline $\begin{array}{l}\text { CS lifetime health and } \\
\text { social care cost }\end{array}$ & 651387.47 & - & - & Gamma & $\begin{array}{l}\text { Average additional lifetime health and } \\
\text { social costs attributable to CS based } \\
\text { on cost estimate for cerebral palsy } \\
\text { (estimate from 2000). }{ }^{22}\end{array}$ \\
\hline
\end{tabular}

For costs, high and low values are $\pm 20 \%$ of baseline values with exception of syphilis screening cost where high and low values are $\pm 50 \%$.

*IUFD refers to the death of a baby in the uterus at $\geq 20$ weeks gestation that is, stillbirth.

†Neonatal death refers to the death of a baby within the first 28 days after birth.

¥These probabilities refer to the final diagnosis after all diagnostic testing plus discussion with sexual health consultant if diagnostic tests result is positive for treponemal antibodies.

CS, congenital syphilis; EIA, enzyme immunoassay; SASS, Surveillance of Antenatal Syphilis Screening.

inflated to $2017 / 2018$ prices using mid-year conversion rates. $^{20}$

\section{Outcomes}

The primary outcome was cost to avoid one case of CS. Secondary outcomes were: cost to avoid one case of IUFD or neonatal death; the number of women who need to be screened to avoid one case of CS, IUFD or neonatal death; and the number of women who need to be treated for syphilis to avoid one case of CS, IUFD or neonatal death.

\section{Sensitivity and scenario analyses}

A univariate deterministic sensitivity analysis (DSA) was run for all probabilities and costs to determine which parameters had the greatest impact on the outcome of the model. This was done by selecting a high and low value for each input and generating outcomes. A probabilistic sensitivity analysis (PSA) using Monte-Carlo simulation (1000 iterations) was used to assess the robustness of the results and calculate $95 \%$ credibility intervals for each output using the mean and standard deviation. A beta distribution was used for clinical probability inputs, and a gamma distribution for cost inputs (table 1).

As well as the base case analysis, seven scenarios were assessed to observe how changes in model assumptions and certain parameters impacted the main outcomes:

1. Lifetime time horizon with incremental costeffectiveness ratio (ICER) in terms of cost per qualityadjusted life year (QALY) as the main outcome. 
2. Incomplete uptake of the repeat screen-where the probability of having a second screen was $99.6 \%$, in line with the current uptake of screening in England.

3. Increased syphilis incidence-varying incidence at 10 intervals between the baseline and the high value used in sensitivity analysis $(0.012 \%)$.

4. No late presentation to antenatal care-all women are screened twice in the repeat screening strategy.

5. $100 \%$ sensitivity and specificity of the syphilis screening process.

6. $100 \%$ specificity of the repeat screen (ie, no false positives).

7. Examining the per screen cost required to meet the standard National Institute for Health and Care Excellence (NICE) cost-effectiveness threshold of $£ 20$ $000-£ 30000 .^{21}$

In scenario analysis 1 , the lifetime healthcare and social care costs for infants born with CS were considered. Since no data on the lifetime cost of CS were available, cerebral palsy (CP) was used as a proxy as it can also lead to a range of disabilities, vary hugely in severity, and may sometimes be a result of CS. The lifetime health and social care costs of CP were taken from a single Danish study ${ }^{22}$ adjusted to reflect UK life expectancy and gender split.

As EuroQol five-dimensions (EQ-5D) data have not been reported for CS or CP, a utility of 0.74 for infants with CS relative to a score of 1.00 for infants born with no CS was used, adapted from a 2006 study of new-born screening strategies where 0.74 was used for infants with 'mild developmental delay'. ${ }^{23}$ These utility values were used in a similar health economic model from the $\mathrm{USA}^{16}$ and were used to calculate QALYs. In the absence of data on changes to utility for infants born with CS, it was assumed that the difference in utility between infants born with CS and infants with no CS remained constant through childhood and adulthood.

Parental HRQoLs were not considered, as this would add complexity to the model. There are no published data on many of the utility scores for each of the pregnancy outcomes, for maternal syphilis diagnosis or receiving a false negative result. These would need to be based on uncertain estimates or from expert opinion, due to limited evidence on HRQoL.

The life expectancy of infants with CS was estimated as 70 years, in line with the estimate for $\mathrm{CP}^{22}$ and in light of reports of CS diagnoses in a wide range of ages. ${ }^{24}$ The life expectancy of infants with no CS was estimated as 81 years based on current UK data. ${ }^{25}$ All costs and utilities were discounted at 3.5\%, in line with NICE guidelines for England. ${ }^{26}$ In DSA, discounting of utilities was varied from $0 \%$ to $6 \%$.

\section{Patient and public involvement}

There was no patient or public involvement (PPI) in the design of the evaluation. A report outlining the model was reviewed by the UK NSC which has PPI representation and was made available for public consultation.
RESULTS

\section{Base case analysis}

The base case results indicate that in 1 year of screening pregnant women in the UK $(\mathrm{n}=725891)$, the repeat screening strategy would result in 5.5 fewer cases of CS, 2 fewer cases of preterm delivery, 0.1 fewer cases of neonatal death (ie, one less neonatal death every 10 years on average), and 0.3 fewer cases of IUFD compared with the single screening strategy (table 2).

The healthcare costs would be $£ 9886863$ higher for the repeat screening strategy (£1 777469008 vs £1 787 355870 , respectively, when total annual screening costs, treatment costs and delivery costs for all pregnant women screened were considered) with most of this increase (£9 $162355)$ being a result of the additional screening costs (table 3).

The model calculated that 124292 women would need to be rescreened in the third trimester to prevent one case of CS, 2.6 million to prevent one case of IUFD (ie, one case prevented approximately every 3.6 years if every pregnant woman was rescreened), and 5.5 million to prevent one case of neonatal death (ie, one case prevented approximately every 7.6 years if every pregnant woman was rescreened, table 4). It would cost an additional £1 791880 per case of CS prevented, $£ 37852707$ per case of IUFD prevented and $£ 79507578$ per neonatal death prevented. An additional 251 women need to receive treatment for syphilis to prevent one case of CS (table 4).

\section{Sensitivity and scenario analyses}

The DSA results indicated that even accounting for parameter uncertainty, the total cost of the repeat screening strategy was always higher than the cost of the single screening strategy (see online supplemental figure S2 for Tornado diagram). Total costs were most sensitive to changes in the per screen cost, but also to changes in the specificity of the screening process, the proportion of women first attending antenatal care before their third trimester, syphilis incidence and the cost of syphilis treatment (online supplemental figure S2). In the DSA examining the impact of clinical and cost parameters on the number of CS cases, the model was most sensitive to syphilis incidence during pregnancy and the probability of CS in infants born to women infected with syphilis during pregnancy who did not receive treatment (ie, were undiagnosed; see online supplemental figure S3). In all iterations in the 1000 PSA Monte Carlo simulations, the repeat screening strategy cost more than the single screening strategy and resulted in fewer cases of CS. The incremental cost and incremental cases of CS prevented are shown in online supplemental figure S4.

When lifetime costs and utilities were considered (scenario 1), the health and social care cost per additional QALY gained for the repeat screening strategy (ICER) was £120 494. In DSA, the ICER was £32 716 and $£ 205600$, when discounting of utilities was $0 \%$ and $6 \%$, respectively (see online supplemental table S15). Even if 
a lower discounting rate were considered by NICE in the future, it is unlikely that $0 \%$ discounting would be used.

In further scenario analyses, reducing the uptake of repeat testing to $99.6 \%$ (in line with current uptake of the first screen, Scenario 2), including all women who attended antenatal care before their third trimester (ie, no late first screen, scenario 4), including $100 \%$ sensitivity and specificity of the screening process (scenario 5 ), or including no false positives in the second screen (scenario 6) had very little impact on the model outcomes, reducing the base case cost per CS case avoided by $<10 \%$ (data not shown).

When the probability of becoming infected with syphilis between screens was increased sevenfold to 0.00012 (scenario 3), repeat screening resulted in 39 fewer cases of CS compared with single screening, 0.9 fewer neonatal deaths, 13 fewer preterm deliveries, and 1.8 fewer cases of IUFDs while the repeat strategy cost an additional $£ 9$ 638476 (online supplemental tables S16 and S17). In this scenario, the cost per CS case prevented was £247 284 (online supplemental table S18). Online supplemental table S19 in the online supplement presents the cost per case of CS avoided and the ICER when the probability of becoming infected with syphilis between screens is higher than baseline (at 10 intervals between 0.00003 and 0.00012). As anticipated, with each increase in incidence, the repeat screening strategy resulted in more CS cases prevented and a lower cost per CS case prevented. When lifetime healthcare and social-care costs were considered, the ICER was $£ 11171$ (below the £20-£30k threshold used by NICE), when syphilis incidence in pregnancy was $0.004 \%$ and became cost saving at an incidence of $0.005 \%$ (1 in 100000$)$ or higher.

Scenario 7 examined the cost per screen needed to meet NICE ICER thresholds (at the current syphilis incidence) (see online supplemental table 20). The per screen cost would need to decrease from $£ 13.36$ to $£ 6.46$ to take the ICER below $£ 30 \mathrm{k}$ and $£ 5.70$ to take it below $£ 20 \mathrm{k}$ when lifetime health and social care costs and utilities of CS were considered.

\section{DISCUSSION}

We report on the cost-effectiveness of repeat universal syphilis antenatal screening in the UK. Our results indicate that this screening strategy would not be costeffective in the current UK setting where the prevalence and incidence of syphilis among pregnant women is low. Although the repeat screening strategy is likely to result in fewer cases of CS, the number of cases prevented would be small, 5-6 a year, and would cost an additional £9.9 million, equivalent to $£ 1.8$ million per case prevented. Most of the increase in cost is a result of the additional costs related to providing the second screen rather than treatment or delivery costs for women with syphilis.

The PSA and DSA indicated that the model results are robust to changes in the inputs. When lifetime health and social care costs and health-related quality of life 
Table 3 Base case short-term annual healthcare costs from model comparing universal repeat screening of syphilis in late pregnancy with single screening

\begin{tabular}{|c|c|c|c|c|}
\hline \multirow[b]{2}{*}{ Screening strategy } & \multirow[b]{2}{*}{$\begin{array}{l}\text { Total healthcare } \\
\text { costs }\end{array}$} & \multicolumn{3}{|l|}{ Cost breakdown* } \\
\hline & & $\begin{array}{l}\text { Antenatal syphilis } \\
\text { screening }\end{array}$ & $\begin{array}{l}\text { Syphilis } \\
\text { treatment } \\
\text { (in pregnant } \\
\text { women found } \\
\text { positive) }\end{array}$ & $\begin{array}{l}\text { Perinatal costs } \\
\text { (for all } \\
\text { pregnancies) }\end{array}$ \\
\hline \multicolumn{5}{|l|}{ Existing: single screen } \\
\hline Estimate & $£ 1777469008$ & $£ 9697904$ & $£ 535434$ & $£ 1767235670$ \\
\hline $\begin{array}{l}\text { Lower } 95 \% \mathrm{Cl} \\
\text { Upper } 95 \% \mathrm{Cl}\end{array}$ & $\begin{array}{l}£ 1769393140 \\
£ 1778772048\end{array}$ & $\begin{array}{l}£ 9661636 \\
£ 9822870\end{array}$ & $\begin{array}{l}£ 532820 \\
£ 545591\end{array}$ & $\begin{array}{l}£ 1759111560 \\
£ 1768490710\end{array}$ \\
\hline \multicolumn{5}{|c|}{ Alternative: repeat screen } \\
\hline Estimate & $£ 1787355870$ & $£ 18860259$ & $£ 970254$ & $£ 1767525357$ \\
\hline $\begin{array}{l}\text { Lower } 95 \% \mathrm{Cl} \\
\text { Upper } 95 \% \mathrm{Cl}\end{array}$ & $\begin{array}{l}£ 1779322118 \\
£ 1788703813\end{array}$ & $\begin{array}{l}£ 18786836 \\
£ 19100346\end{array}$ & $\begin{array}{l}£ 964636 \\
£ 989342\end{array}$ & $\begin{array}{l}£ 1759402583 \\
£ 1768782187\end{array}$ \\
\hline Cost difference & $£ 9886863$ & $£ 9162355$ & $£ 434820$ & $£ 289687$ \\
\hline
\end{tabular}

${ }^{*}$ Costs to the NHS in the UK for all 725891 pregnant women screened. Costs are spilt into (1) antenatal screening costs, which includes sample collection and laboratory testing; (2) syphilis treatment within sexual health clinics and (3) perinatal costs, which includes the costs of delivery and neonatal care for all infants.

NHS, National Health Service.

(HRQoL) were considered (Scenario 1), the cost per QALY gained was $£ 120494$ for the repeat screening strategy compared with the single screening strategy. This is well above the £20k-£30k cost per QALY threshold that NICE uses to assess interventions, ${ }^{21}$ and also exceeds the $£ 100000$ threshold used to assess drugs/interventions for rare conditions (the threshold used when the intervention results in $<10$ additional QALYs to an individual in their lifetime). ${ }^{27}$ For this analysis, costs and utilities were discounted by $3.5 \%$, in line with NICE guidelines for England. ${ }^{26}$ When no discounting of utilities was assessed in DSA, the cost per QALY gained was $£ 32716$, just above the $£ 30 \mathrm{k}$ threshold.

Only two previous economic evaluations have assessed universal repeat syphilis screening in pregnancy compared with single screening in early pregnancy, both in the USA. Albright et al reported that repeat thirdtrimester screening would prevent 60 CS cases per 4 million women costing US\$419 842 per case avoided, concluding that repeat screening was not cost-effective. ${ }^{17}$ Hersh et al found that repeat screening would prevent 41 CS cases per 3.9 million women and result in total cost savings of US $\$ 52$ million. ${ }^{16}$ Neither study accounted for late presentation to antenatal care-syphilis prevalence and incidence were considerably higher than in the UK as were healthcare costs.

It is important to note that changes to the screening strategy would not change the number of adverse pregnancy outcomes in women who decline screening, in women who present late to antenatal care and have one screen but no opportunity for a repeat screen, or in women who first present at the time of delivery, thereby missing the opportunity for any antenatal screening or treatment. For this reason, and because treatment for syphilis is not universally effective at preventing adverse pregnancy outcomes, it is likely that there would continue to be a very small number of infants born with CS each year irrespective of changes made to the screening strategy.

\section{Strengths and weaknesses}

This is the first health economic analysis to assess the costs and clinical benefits of a repeat screening strategy for syphilis compared with a single screen strategy within the UK setting. The input values in the model were based on the best available evidence from the published literature,

Table 4 Requirements to prevent one outcome-from model comparing universal repeat screening of syphilis in late pregnancy with single screening

\begin{tabular}{lllll}
\hline Outcome & Cost & $\begin{array}{l}\text { Women } \\
\text { screened in } \\
\text { third trimester }\end{array}$ & $\begin{array}{l}\text { Women treated } \\
\text { for syphilis-TP } \\
\text { and FP }\end{array}$ & $\begin{array}{l}\text { Additional } \\
\text { false } \\
\text { positives }\end{array}$ \\
\hline Congenital syphilis & $£ 1791880$ & 124294 & 251 & 249 \\
Intrauterine fetal demise & $£ 37852707$ & 2625664 & 5300 & 5251 \\
Neonatal death & $£ 79507578$ & 5515066 & 11133 & 11030 \\
\hline
\end{tabular}

FP, false positive; TP, true positive. 
UK-specific surveillance data, NHS tariffs and published costs, and with input from experts in the field where data were lacking. These inputs were rigorously tested in sensitivity and scenario analyses to add confidence to the results, despite limited data in some areas.

There were sparse UK data available on pregnancy outcomes in women treated for syphilis or in infants born with CS. There are no published EQ-5D scores for CS and a lack of evidence on changes to utility and health and social care costs over time for infants born with CS. We therefore used the additional lifetime cost of CP, estimated in a study from Denmark, ${ }^{22}$ as a proxy for the lifetime cost of CS. As such, the primary focus of the analysis was the short-term costs and CS cases avoided since it was difficult to have confidence in the estimate used for lifetime CS cost or utility.

The model assumed that women could not become infected with syphilis between the repeat screen and delivery. As the incidence estimate relates to the full duration of pregnancy, this assumption would overestimate the number of women diagnosed and treated at the repeat screen, thereby overestimating the benefits of the repeat screen strategy. However, the number of women who become infected with syphilis during pregnancy is small and as such this would have little impact on the overall results. Since we do not know what repeat screening coverage would be, the model assumed 100\% coverage, since all women in the model had already agreed to a first screen. This is optimistic, since it assumes continued engagement with antenatal services. However, scenario analysis 2 showed that even when uptake was $<100 \%$ it would be unlikely to have much impact on the cost per CS case avoided.

It was also assumed that all women and neonates diagnosed with syphilis receive the appropriate full course of treatment and all infants born to women diagnosed with syphilis in pregnancy receive syphilis testing at birth. However, the SASS study ${ }^{13}$ found that in 2010-2011, not all women diagnosed with syphilis received complete treatment and inadequate paediatric follow-up was identified as an issue. Lack of treatment in these women and neonates is likely to make the repeat screening even less cost-effective.

Since there are no published estimates of the diagnostic accuracy (DA) of the syphilis screening process, accounting for the DA of laboratory assays and the diagnosis decision making by clinicians, average sensitivity and specificity of EIA assays used in UK laboratories were used. ${ }^{28}$ The DA values used here are considerably higher than those used in the US models,${ }^{16}{ }^{17}$ where a different testing algorithm is used ${ }^{29}$ and would, if anything, bias repeat screening results towards being more cost-effective.

\section{Implications for clinicians and policy-makers}

The number of CS cases was most sensitivity to changes in the syphilis incidence between screens. It may be costeffective to repeat screen for a period of time where there is a known syphilis outbreak or if there are multiple cases of CS in a short period within the same geographical area in women who tested negative for syphilis at the first screen-as this would indicate a much higher syphilis incidence in pregnancy in that area.

Our model focused on the UK but is relevant to other European countries with similar syphilis prevalence and healthcare costs. Our analyses, using UK cost estimates, suggest that a universal second screen in late pregnancy could become cost-effective if the incidence of syphilis in pregnancy were to increase (to 5 per 100000 pregnant women), indicating that in countries that have far higher syphilis prevalence than the UK, a second screen could be cost saving. For example, recent estimates suggest that the prevalence of syphilis in the WHO African region is more than 10-fold higher than in the WHO European Region. ${ }^{30}$ In such a high prevalence setting, combined with lower local healthcare costs, a second syphilis screen in late pregnancy could be cost-effective.

There could be some negative impact associated with repeat screening. A false positive result may lead to additional costs, unnecessary anxiety for mothers and their families, impact the mother's relationships, possibly even damage their confidence in the screening programme, as well as lead to overtreatment. It is vital to minimise unnecessary use of antibiotics where possible given growing concerns around antimicrobial resistance and because there is some evidence that antibiotic use in pregnancy increases the risk of childhood epilepsy, obesity and asthma. $^{31}$

Alternative approaches to reduce the number of CS cases and other adverse pregnancy outcomes could be more cost-effective and should be explored. These include better targeting of high-risk individuals and sexual health promotion in pregnancy. Furthermore, of the $20 \mathrm{CS}$ cases in the UK since 2010, 11 had no record of the mother receiving antenatal screening. It remains unknown whether this was because testing was refused or due to very late/no first antenatal attendance. ${ }^{15}$ This highlights the need to ensure timely screening in pregnancy, particularly in women who present late who are already at increased risk of adverse pregnancy outcomes. Education for pregnant women around sexual health and STI prevention might be cost-effective and could be considered.

\section{Unanswered questions and future research}

Our model had a single disease focus. At present, however, pregnant women are screened for syphilis, HIV and hepatitis B. It would be useful to assess the potential cost-effectiveness of a repeat screen for all three infections since treatment for these infections during late pregnancy and/or at birth would reduce the risk of vertical transmission. Screening for all three infections may yield more benefits in terms of clinical outcomes and may make this strategy more cost-effective.

Furthermore, data collection including gestational week of first screen, coverage of repeat screen in highrisk women, pregnancy outcome for women treated for 
syphilis, stage of infection in women diagnosed with syphilis and cost estimation for lifetime costs of being born with CS, would help inform future evaluations of screening strategies.

\section{CONCLUSIONS}

The results of this health economic analysis indicate that implementing universal repeat screening for syphilis in pregnancy is unlikely to be cost-effective in the current UK setting where the prevalence and incidence of syphilis in pregnant women is low. Repeat screening could be considered in areas with a high syphilis incidence in pregnancy and may then be cost-effective, particularly if the cost per screen is low.

If syphilis prevalence continues to increase, the costeffectiveness of the repeat screening strategy should be re-examined, highlighting the importance of continued monitoring of syphilis in pregnant women, screening uptake, CS cases and long-term follow-up.

\author{
Author affiliations \\ ${ }^{1}$ Aquarius Population Health Ltd, London, UK \\ ${ }^{2}$ UK National Screening Committee, Public Health England, London, UK \\ ${ }^{3}$ UCL Institute for Global Health, University College London, London, UK \\ ${ }^{4}$ Department of Paediatric Infectious Diseases \& Immunology, Evelina London \\ Children's Hospital, London, UK \\ ${ }^{5}$ Department of Paediatrics, The Royal Children's Hospital Melbourne, Melbourne, \\ Victoria, Australia \\ ${ }^{6}$ School of Veterinary Science, University of Bristol, Bristol, UK
}

Twitter Susie Huntington @AquariusPH, Katy Turner @katymeturner and Elisabeth Adams @aquariusph

Acknowledgements We would also like to thank the following people for their contributions to this work: Nicola Bowers, Helen Fifer, Lyn Hutchison, Margaret Kingston, Anne Mackie, Paddy McMaster, Catherine Peckham, lan Simms, Judith Timms and Sharon Webb.

Contributors The model structure was developed by SH, with input from GW, FS and JM. The final model structure was informed by input from JM, HB, MT, IA, KT and EA. SH developed the model parameters with input from MT, IA, GW, HB, FS, JM and KT. SH drafted the paper. All authors contributed to the interpretation of the results and contributed to the contents of the paper. All authors have approved the final submitted version.

Funding Award/Grant number is not applicable.

Competing interests SH, GW and EA work at Aquarius Population Health and have received consultancy fees from the following companies on projects related to STIs: Abbott, Cepheid, Binx Health, Hologic and St. Georges University of London. IA, KT and MT were funded as consultants on the project through Aquarius Population Health. MT has received support from Cepheid for conference attendance. KT is in receipt of funding to University of Bristol from GlaxoSmithKline for work unrelated to this work.

Patient consent for publication Not required.

Provenance and peer review Not commissioned; externally peer reviewed.

Data availability statement All data relevant to the study are included in the article or uploaded as online supplemental information.

Supplemental material This content has been supplied by the author(s). It has not been vetted by BMJ Publishing Group Limited (BMJ) and may not have been peer-reviewed. Any opinions or recommendations discussed are solely those of the author(s) and are not endorsed by BMJ. BMJ disclaims all liability and responsibility arising from any reliance placed on the content. Where the content includes any translated material, BMJ does not warrant the accuracy and reliability of the translations (including but not limited to local regulations, clinical guidelines, terminology, drug names and drug dosages), and is not responsible for any error and/or omissions arising from translation and adaptation or otherwise.

Open access This is an open access article distributed in accordance with the Creative Commons Attribution Non Commercial (CC BY-NC 4.0) license, which permits others to distribute, remix, adapt, build upon this work non-commercially, and license their derivative works on different terms, provided the original work is properly cited, appropriate credit is given, any changes made indicated, and the use is non-commercial. See: http://creativecommons.org/licenses/by-nc/4.0/.

\section{ORCID iDs}

Susie Huntington http://orcid.org/0000-0002-2854-7441

Georgie Weston http://orcid.org/0000-0003-3019-7150

Farah Seedat http://orcid.org/0000-0002-3563-7875

John Marshall http://orcid.org/0000-0002-6239-774X

Heather Bailey http://orcid.org/0000-0003-3266-1041

Katy Turner http://orcid.org/0000-0002-8152-6017

Elisabeth Adams http://orcid.org/0000-0002-4222-9394

\section{REFERENCES}

1 Public Health England. Sexually transmitted infections (STIs): Annual Data Tables 2014-2018, 2019. Available: https://www.gov.uk/ government/statistics/sexually-transmitted-infections-stis-annualdata-tables

2 Ricci JM, Fojaco RM, O'Sullivan MJ. Congenital syphilis: the University of Miami/Jackson Memorial medical center experience, 1986-1988. Obstet Gynecol 1989;74:687-93.

3 Sheffield JS, Sánchez PJ, Morris G, et al. Congenital syphilis after maternal treatment for syphilis during pregnancy. Am J Obstet Gynecol 2002;186:569-73.

4 Gomez GB, Kamb ML, Newman LM, et al. Untreated maternal syphilis and adverse outcomes of pregnancy: a systematic review and meta-analysis. Bull World Health Organ 2013;91:217-26.

5 De Santis M, De Luca C, Mappa I, et al. Syphilis infection during pregnancy: fetal risks and clinical management. Infect Dis Obstet Gynecol 2012;2012:1-5.

6 Mwaniki MK, Atieno M, Lawn JE, et al. Long-Term neurodevelopmental outcomes after intrauterine and neonatal insults: a systematic review. The Lancet 2012;379:445-52.

7 Arnold SR, Ford-Jones EL. Congenital syphilis: a guide to diagnosis and management. Paediatr Child Health 2000;5:463-9.

8 NHS Digital. NHS Maternity Statistics, England 2017-18, 2018. Available: https://digital.nhs.uk/data-and-information/publications/ statistical/nhs-maternity-statistics/2017-18 [Accessed 19 Jun 2019].

9 PHE and NHS. NHS Infectious Diseases in Pregnancy Screening Programme Screening Standards Data Report 1 April 2016 to 31 March 2017, 2019. Available: https://www.gov.uk/government/ publications/infectious-diseases-in-pregnancy-screening-standardsdata-report [Accessed 21 May 2019].

10 Public Health Agency, Belfast. Sexually transmitted infection surveillance in Northern Ireland. An analysis of data for the calendar year 2016, 2017. Available: https://www.gov.uk/government/ statistics/sexually-transmitted-infections-stis-annual-data-tables

11 Public Health England. NHS Infectious Diseases in Pregnancy Screening Programme Handbook 2016 to 2017, 2016. Available: https://www.gov.uk/government/publications/infectious-diseases-inpregnancy-screening-programme-handbook

12 Public Health England. Screening tests for you and your baby. Important information about the screening choices you will have during and after your pregnancy. NHS booklet, 2020. Available: https://assets.publishing.service.gov.uk/government/uploads/ system/uploads/attachment_data/file/865122/Screening_tests_for you and your baby information leaflet.pdf

13 Townsend CL, Francis K, Peckham CS, et al. Syphilis screening in pregnancy in the United Kingdom, 2010-2011: a national surveillance study. BJOG: Int J Obstet Gy 2017;124:79-86.

14 World Health Organization. Global guidance on criteria and processes for validation: elimination of mother-to-child transmission (EMTCT) of HIV and syphilis. Geneva World Health Organization; 2013. https://www.who.int/reproductivehealth/publications/emtcthiv-syphilis/en/

15 Furegato $\mathrm{M}$, Fifer $\mathrm{H}$, Mohammed $\mathrm{H}$, et al. Factors associated with four atypical cases of congenital syphilis in England, 2016 to 2017 : an ecological analysis. 2017;22.

16 Hersh AR, Megli CJ, Caughey AB. Repeat screening for syphilis in the third trimester of pregnancy: a cost-effectiveness analysis. Obstet Gynecol 2018;132:699-707. 
17 Albright CM, Emerson JB, Werner EF, et al. Third-Trimester prenatal syphilis screening: a cost-effectiveness analysis. Obstet Gynecol 2015;126:479-85.

18 Qin J, Yang T, Xiao S, et al. Reported estimates of adverse pregnancy outcomes among women with and without syphilis: a systematic review and meta-analysis. PLoS One 2014;9:e102203.

19 XE Currency Converter. Available: https://www.xe.com/

20 Curtis L, Burns A. Unit costs of health and social care 2018, personal social services research unit, University of Kent, Canterbury, 2018. Available: https://www.pssru.ac.uk/project-pages/unit-costs/unitcosts-2018/

21 National Institute for Clinical Excellence. Guide to the methods of technology appraisal 2013, 2013. Available: https://www.nice.org. uk/process/pmg9/resources/guide-to-the-methods-of-technologyappraisal-2013-pdf-2007975843781

22 Kruse M, Michelsen SI, Flachs EM, et al. Lifetime costs of cerebral palsy. Dev Med Child Neurol 2009;51:622-8.

23 Carroll AE, Downs SM. Comprehensive cost-utility analysis of newborn screening strategies. Pediatrics 2006;117:S287-95.

24 Probst LE, Wilkinson J, Nichols BD. Diagnosis of congenital syphilis in adults presenting with interstitial keratitis. Can J Ophthalmol 1994;29:77-80

25 Office for National Statistics. National Life Tables, UK: 2016 - 2018, 2019. Available: https://www.ons.gov.uk/peoplepopulationandc ommunity/birthsdeathsandmarriages/lifeexpectancies/bulletins/nat onallifetablesunitedkingdom/2016to2018 [Accessed 1 Oct 2019].

26 National Institute for Health and Care Excellence. How should NICE assess future costs and health benefits. NICE citizens Council meeting, 2020. Available: https://www.nice.org.uk/Media/Default/ Get-involved/Citizens-Council/Reports/CCReport15Discounting. pdf

27 Powell T, O'Donnell M. House of commons debate pack. NICE appraisals of rare diseases, 2019. Available: http://researchbriefings. files.parliament.uk/documents/CDP-2019-0022/CDP-2019-0022.pd

28 Public Health England. Data on EIA assays used in UK supplied by lead microbiologist for bacterial STIs at the National infection service; 2019.

29 Morshed MG, Singh AE. Recent trends in the serologic diagnosis of syphilis. Clin Vaccine Immunol 2015;22:137-47.

30 Rowley J, Vander Hoorn S, Korenromp E, et al. Chlamydia, gonorrhoea, trichomoniasis and syphilis: global prevalence and incidence estimates, 2016. Bull World Health Organ 2019:97:548-62.

31 Kuperman AA, Koren O. Antibiotic use during pregnancy: how bad is it? BMC Med 2016;14.

32 Shiber L, Todia WJ. Cost and clinical utility of repeated syphilis screening in the third trimester in a high-risk population. Am J Obstet Gynecol 2014;210:267.e1-267.e5.

33 Pathway Analytics. Integrated Sexual Health Tariff - London ISHT 2017/2018. Available: https://www.pathwayanalytics.com/

34 Campbell HE, Kurinczuk JJ, Heazell A, et al. Healthcare and wider societal implications of stillbirth: a population-based cost-of-illness study. BJOG 2018;125:108-17.

35 Khan KA, Petrou S, Dritsaki M, et al. Economic costs associated with moderate and late preterm birth: a prospective population-based study. BJOG: Int J Obstet Gy 2015;122:1495-505. 